\title{
(W)reading, Wrangling and the Rhythm of the Text: Enhancing the Education of Young Boys with Game-Based Learning
}

\author{
Katherine Blashki
}

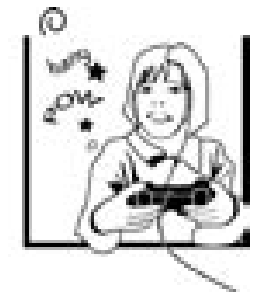

$\mathrm{C}$ onnecting curriculum content to young people's engagement with texts outside of the classroom is increasingly recognized as a method of providing challenging learning environments (Beavis 1999). The introduction of games-based learning in areas such as literacy provides young people with a structural and conceptual framework with which many, particularly young males, may be familiar. Exploiting the recreational interactive behaviour of 'game geeks' to enhance classroom learning may go some way towards ameliorating many of the notorious social, cultural and educational issues currently faced by teachers of young males.

This paper discusses the development of tools, and suggests possible guiding principles, for enhancing the learning environments of young males and consequently increasing the potential for successful and fulfilling learning experiences. The application of such principles augments the ability of children to develop, and respond with, cultural and critical competencies that we might designate as 'media literacy', thus concomitantly increasing the access to, and enjoyment of, reading a diversity of texts. For such an educational method to succeed it should acknowledge the nature of the immersive experience for boys as one which is distinguished by both physical and emotional modes of engagement, and which may be different from the kinds of engagement girls experience.

\section{(W)reading}

West (2002) notes the danger period of years 8 and 9 (14-15 years of age) as the prime focus for improving strategies for boys' literacy. Much of the research similarly points to reading and writing as crucial areas of concern in the education of young boys. Competence in reading and writing is the result of highly specific techniques, trainings and applications of knowledge, learned techniques of representation along with the other visual, aural and kinaesthetic forms of representation. As explored by Gee, when playing video games we are learning a new type of literacy, 'a multi-modal literacy' (2003:14). Thus writing, or authoring a game, is not simply a matter of finding the right words, the right sounds and images in order to 'translate' an entirely spontaneous act of artistic creativity. Rather, readers/players recognise a group of words, sounds and images as a 'game' by applying particular techniques, learned expectations for connecting those word, sound and image elements into a pattern we designate as 'game'. It is these learned 'reading' behaviours, these patterns of order and expectation that we impose upon our 'reading'/ interaction, that form the meanings we derive from the text. In some respects, we have always re-written the texts we encounter, inscribing our own 'stories' on the text. We have always been both reader and writer, game-player and developer.

The author is not dead as claimed by the more zealous exponents of both Barthesian and post-structuralist musings and writings within a digital environment, but rather the idea of an 'author' has evolved into a new hybrid textual participant-the 'wreader'(Moulthrop 1995). The 'wreader' provides a useful conceptualisation for understanding the interaction a young male has with a game. The term 'wreader' subtly hybridises the traditional polarities of reader and writer in a Derridean differance in that it not only designates the gamer/user as both reader and writer/author, but also offers its own frustrating and unstable meaning of a graphic depiction of the very reading-writing process at work; the slippage between the signifier and the signified - the game and the interactive use the gamer makes of it. The agency the interventions permit within the text/game by the wreader/player ensures the game geek's willing immersion in the text. Wreader thus transgresses the familiar threshold of signification and becomes a floating signifier of sorts.

\section{Wrangling with the rhythm of the text}

Any brief sojourn into the world of boys demonstrates that mobility/motion is the defining characteristic of young males' interaction with play objects. Anecdotal observation demonstrates that far from being sedentary, quiet and powerless, when a boy moves with the joystick, console or mouse, he is actively involved in whole body movement with the game - boys will move with the rhythmic cadences of the movement of the gameplay: running, jumping, riding, throwing, 'wrangling' with the virtual world, his body in rhythmic alliance with the text before him. When he interacts with a game he enjoys, a young boy's experience is characterised by immersion and sustained attention as well as a real sense of agency in the gameplay. As West (1999b) suggests, the body is central to 
a boy's ideas about himself, and it is more often through the physicality of his body that a boy will be moved to express emotion or feeling.

\section{Educating boys}

As an example of a game that integrates the engagement and entertainment potential of games with curriculum content for learning, Atlantis (Floyd and Blashki, 2003) was specifically designed to exploit the spatial proficiency of boys for navigation within a game environment that explores an imaginary world from within a social studies framework. The presence of a compass in the top right of the screen orientates the player within a three dimensional space. The player has freedom within the world of Atlantis to physically cross the boundaries that ordinarily proscribe movement within their 'real' world. The player can quite literally 'fly', move through walls, hide from others as if invisible and generally participate in activities only dreamed of or fantasised about in other play activities, thus fundamentally transforming the player's experience of 'learning'.

Gardner's (1983) theoretical premise based on multiple intelligences has been directly applied in the development of the game Atlantis via the formulation of tasks and objectives relating to specific intelligences. An example is a number of tasks within the game are visual/spatial in nature designed to enable children who best learn within the parameters of that category reach their full potential and gain maximum results from using the learning tool. The player is directed by movement on the screen to 'look for' clues that might reveal further information to complete a task. To encourage 'reading', instructions are written in a text box above the activity and articulate the player's intuitive physical movement, affirming their spatial familiarity and in addition, enhancing literacy skills in a non-threatening, 'non-reading', environment. Bloom and Krathwohl's (1956) hierarchical taxonomy assists in the formulation of questions, objectives and challenges within the game structure that students will readily understand, while concurrently extending their knowledge base into new domains. This is achieved via the integration of such questions and challenges with increasing degrees of abstraction that correspond to the levels of Bloom's learning hierarchy.
Rowe (2004) suggests that curriculum needs to be more attractive to boys and conducive to the ways in which they learn most effectively. Implementation of suitable teaching strategies within a Science program has proven successful in an Australian school, Lumen Christi College, where teachers exploited boys' familiarity and association with information technology as an enjoyable activity. West (2002) similarly calls for more active learning in the curriculum, yet also points to the need for structured learning, suggesting mentoring as an important factor in the education of boys as they are particularly susceptible to peer influence. West cites a successful program at an Australian private boys' school, King's College, as an example of the improvements such changes can generate. West (1999a; 1999b; 2002) points to long-term decline in boys' academic performance relative to girls and suggests that teacher flexibility in curriculum development and implementation is important to channel boys' energy and exuberance into appropriate activities for learning.

O’Sullivan (1997) describes poor literacy performance as the progenitor of an 'anti-academic ethos'(p.E8), and cites a study of 3,200 five year olds in Surrey, England which indicates that typically boys develop the skills for literacy later than girls and, as toddlers, for example, are more focused on activity and the manipulation of their surrounding environment. In $T V M$, a program designed to include a range of age-appropriate games in a digital environment, Ellis and Blashki (2004) similarly found that very young males could maintain sustained focus on a task provided active manipulation was permitted. Ellis \& Blashki (2004) found that when children, both male and female, are provided with developmentally appropriate digital games, then learning was an enjoyable adjunct to playing. Active engagement and immersion in the playing process of the program $T V M$ ensured the acquisition of a wide range of cognitive skills in children as young as 18 months old. Of particular interest was the increase in the ability to sustain focused attention. For instance, one 19month-old male participant in the study remained on task for 75 continuous minutes on the same activity.

Noble and Bradford (2000) delineate several strategies for achieving positive results in the education of boys and conclude that active tasks prove the most successful 


\section{The skill is not physical action (as for the heroes represented in the games) but rather cognitive and strategic and based on intensive practice.}

strategy for promoting participation and learning. The provision of practical work in addition to traditional 'book learning,' they argue, will enable boys to successfully relate to a given task. In addition, Noble and Bradford's study indicates that boys prefer audio visual aids such as video, CD-ROM, film and slides in the classroom. Consequently, by implementing learning tools that combine a boy's successful skill base, physicality and interests, for example, computer studies and games, with an area that requires considerably more development, such as literacy, improvements in both motivation and competency in the learning process are discernable.

Collectively, and combined with well-documented accounts of boys' enjoyment of computer games, the development of game-based learning tools such as Atlantis and TVM could potentially enhance the learning environment of young males, promoting increased motivation and concomitant success. However, action as a behavioural activity does not necessarily guarantee cognitively active learning. Research (Mayer \& Moreno 1998; Krathwohl et al. 2001) indicates that meaningful learning is dependent on the learner's cognitive, rather than behavioural, activity. Indeed, despite the engagement and immersive play required in electronic games, little cognitive activity, of the order espoused in Bloom's taxonomy, may be occurring. It is thus quite possible to be engaged in a hands-on activity such as playing a highly interactive computer game that fails to promote cognitively vigorous learning. It is vital that game designers/developers and educationalists collaborate in the development of gamesbased learning tools. Such collaborations result in games such as Atlantis (Floyd and Blashki 2003) and TVM (Ellis and Blashki 2004) which not only ensure that learning is cognitively meaningful, but also is fun - a significant factor in ameliorating the negative educational experiences of the recalcitrant or disinterested learner.

\section{Learning as social and educational game play}

The creation and implementation of purpose-specific games for young people such as TVM and Atlantis attempt to conceptualise learning, not as a function of the game, but rather as the result of transformations that occur through the player's understandings of social and cultural contexts, which arise from interactions with the dynamic interplay of subject content. In multiplayer games the development and utilisation of social skills are an essential element of the game play. As Aarseth (2001) declared in the inaugural edition of the International Journal of Game Studies, 'computer games are perhaps the richest cultural genre we have yet seen' (p.5).

Games have increasingly attracted the attention of pedagogues, politicians and parents as the instigator of a 'culture of violence'. Such fears that playing computer games is in some way damaging development and nurturing aggressive behaviour are encouraged by populist notions premised on technological determinism(Quigley \& Blashki 2003). Research, however, indicates that game playing can lead to valuable learning outcomes in computer literacy, logical thinking, creativity and co-ordination, maths, spelling and reading skills (McFarlane et al 2001).

Activity theorists such as Engestrom (1987) have attempted to formulate conceptual frameworks which may assist in understanding the complexity of the apparently dichotomous relationship between the interactions that constitute game play and the contexts within which such game play takes place. Thus, how do we reconcile the human activity of playing digital games with its necessary mediation by both the tools required and the cultural, social, political etc context in which they are played? Of particular interest to the author in the application of games to learning is the potential for conflict between objectives of the game: the need to compete and win (particularly in the play of young boys) and the learning of subject content.

What becomes apparent when observing the behaviour of boys and girls whilst playing electronic games (though it is significantly more marked in boys) is the quality and depth of the experience, their level of engagement (Blashki \& Ellis, 2004). This contrasts sharply with observable behaviours associated with school work: reluctance, boredom, recalcitrance. The gamer is energised by the experience, and observed post-game behaviour attests to this (The author acknowledges that such behaviour is frequently noted as not always constructive if it fails to be directed appropriately). In a study trialling the use of games within a classroom setting, McFarlane et al (2001) suggest the use of games in the classroom provides a forum in which learning arises as a result of tasks stimulated by the content of the games, knowledge is developed through the content of the games, 


\section{If video game technology is in fact inherently constructive of a particular view of masculinity, do we want to proliferate its use, thus excluding girls and firming up the gender divide?}

and skills are developed as a result of physically playing the game. McFarlane et al's study found that quest and simulation games (such as Atlantis and the Sims collection) contributed to children's learning in a number of key areas such as: communication, application of number, working with others, problem solving and financial capability.

Whilst children are adept at playing games of all sorts according to rules, any survey of the school playground during lunchtime will attest to children's ability and agility for modification and invention of rules for playing. Such manipulation of rules and procedures is simply part of a child's progression and negotiation through their world, a way of gaining some control over and an understanding of their environment. Children are equally creative in the development and production of their own games. Given the skill and ability of many children in playing commercially-developed electronic games, there is no reason to suppose that similar skills could not be transposed to the development and implementation of their own games. Kafai (1995) investigated game-making with 10 year-oldchildren within the context of learning mathematics and concluded that when assisted with supervision and design directives the students not only produce their own games but also 'generate constructivist game ideas', that is, the 'learner is involved in all the design decisions and begins to develop technological fluency' (Kafai 2001, p.4). In a similar study to Kafai's, the Ludis Vitae project by Jenson $\&$ de Castell (2002) explored the use of design tools as toys which train players in skilled ways to bring educational needs, resources and practices into their play. Such a learning strategy is known as 'stealth learning'; players learn incidentally as their focus is on the rules, structures, tasks and activities within the game.

\section{Games as education}

Prensky (2001) contends that the impetus for games-based learning is premised on two fundamental principles: 'learners have changed in some fundamentally important ways... [and these learners] deeply experienced, for the first time in history, a radically new form of play - computer and video games' (p.16). Thus, the very nature of the learner and the experiential forms of play to which they are accustomed require a very different mode and medium for learning. Prensky advocates a 'new learning paradigm' (p.19), one that will eradicate the major impediment to learning as suggested by Papert, 'The reason most kids don't like school is not that the work is too hard, but that it is utterly boring!' (1998, p.88). Tapscott (1998) further justifies the introduction of new ways of introducing content to learners: 'Today's kids are so bathed in bits that they think it's all part of the natural landscape'(1998, p.1). Jenson \& de Castell (2002) refer to 'digitally mediated educational activity' as providing benefits to the education of school children. An example of a digitally mediated educational game is Learn Technologies Interactive's simulation of an archaeological excavation of $5^{\text {th }}$ century Greek ruin. This game is designed for 2-3 grade children and emphasises analytical and critical thinking skills and cognitive development. Further work has resulted in an adventure game focused on ancient Chinese history and society, Qin. Whilst Qin has sold well (approximately 100,000 copies) such popularity has not resulted in widespread uptake in the school system. It can be argued that too often the exploitation of consumer enthusiasm for games applied to educational purposes results in a commercial hybrid 'edutainment' which barely passes as entertainment let alone education! There is a marked absence of research on the development of games to enhance the learning process of young males in educational settings.

Importantly, games can be usefully and successfully deployed as the primary learning vehicle and not simply for the purposes of review and reinforcement. Game-based learning has considerable capacity for integrating a diversity of subject matter, pedagogic approaches and learning styles. Blashki and Fladen (2004), in a study of Norwegian tertiary students (predominantly male), found that when offered the opportunity to select from (a) a choice of classroombased learning with lectures (b) a classroom-based learning augmented with some games-based learning or (c) a module comprising solely game-accelerated learning, students invariably opted for the latter option initially, then settled into the combination of face-to-face teaching with an added layer of game accelerated learning in which they were agents in the development and creation of content.

It is apparent that we cannot simply transpose traditional classroom curriculum design and delivery and presume it will work in an electronic environment, justifying reduced (if any) attention to game playability as a compromise 
for content. Rieber \& Matzko (2001) explore some of the impediments to a student's engagement citing insistence of developmental assessment, no potential in the game for luck or chance, few opportunities for instant feedback and no room for intuitive leaps, as the prime offenders. Blashki \& Fladen (2004) found that linear movement through tasks or skills that restrict transfer to other tasks/skills until completion was the principal frustration for students in their interaction with many 'educational e-learning' products. For experienced gamers (the average 13 year old male) reduced or negligible twitch speed perception (the inability to accommodate the intuitive leaps Reiber and Matzko discuss) is a major deterrent in sustaining engagement. As the very raison d'être of playing an electronic game, feedback is essential to sustained engagement. It is the very 'pleasure of the text' that ensures the gamer's continued and repeated interaction.

\section{Conclusion}

Hitherto there has been much in the way of discursive rhetoric and little action in the development and design of appropriate games-based learning tools. Prensky's (2001:4) irritation is readily discernable within the academic community: ' ...there are a growing number of pioneers - teachers, trainers, learners...who are creating more and more Digital Game-based learning each day, out of the sheer frustration that it doesn't exist'.

The methodologies currently in use in the education of young males are perilously close to redundancy in a society where many of them willingly and happily turn to technological play, as an adjunct to more traditional forms, for exploring and negotiating their way around information. Rhetorical invocations of 'student-centred learning' are meaningless if we fail to account for alternative methods that may best address the learning needs of specific groups such as young boys. Provision for agency, physical interaction and immersion, both virtually and in reality, are essential in the design and development of curriculum for young males as these are the defining needs of boys' interaction with learning experiences. Whilst the author does not presume games are the definitive answer to all difficulties for all boys, what is clear, is that when games-based learning is used to augment traditional learning modes, young boys are noticeably more amenable to educational content.

\section{REFERENCES}

Aarseth, E.J. (2001) 'Computer game studies year one', International Journal of Computer Game Research, 1, 1 (http://www. gamestudies.org/0101/editorial.html).

Beavis. C. (1999) 'Literacy, English and computer games', The Power of Language, International Federation for the Teaching of English, 7-10 July, University of Warwick, U.K.

Blashki, K. \& Ellis, K. (2004) 'Toddler techies: A study of young children's interaction with computers', Information Technology in Childhood Education Annual 1: 77-96.

Blashki, K. \& Fladen, E. (2004) 'Learning = playing: Interactive learning with gamesbased design principles' (unpublished).

Blashki, K. (2004) 'Social consolation: Girls and the social aspects of playing games' (unpublished).

Bloom, B. \& Krathwohl, D. (1956) Taxonomy of Educational Objectives: The Classification of Educational Goals, by a Committee of College and University examiners. Handbook I: Cognitive Domain. New York.

Ellis, K. \& Blashki, K. (2004) 'Mastering the metaphor: Empowering the young child for independent computer use', EdMedia, World Conference on Educational Multimedia, Lugano, Switzerland, 1: 4438- 4445.

Engestrom, Y. (1987) Learning by Expanding: An Activity-Theoretical Approach to Developmental Research. Helsinki, OrientaKonsultit.

Floyd, B. \& Blashki, K. (2003) 'Gender(ed) learning: Enhancing the education of boys with games-based learning tools' (unpublished).

Gardner, H. (1983) Frames of Mind: The Theory of Multiple Intelligences. New York, Basic Books. 
Gee, James Paul (2003) What Video Games have to Teach about Learning and Literacy. New York, Palgrave Macmillan.

Jenson, J. \& de Castell, S. (2002) 'Serious play: Challenges of educational game design', $A E R A$, New Orleans, April 1-5, Draft Paper.

Kafai, Y.B (1995) Minds in Play: Computer Game Design as a Context for Children's Learning. Hillsdale, NJ, Lawrence Erlbaum Associates.

Kafai, Y.B. (2001) 'The educational potential of electronic games: From games-to-teach to games-to-learn', Playing by the Rules, Cultural Policy Center, University of Chicago, October 27th 2001.

Krathwohl et al. (2001) Taxonomy for Learning, Teaching, and Assessing: A Revision of Bloom's Taxonomy of Educational Objectives. New York, Longman.

Mayer, R. E. \& Moreno, R. (1998) 'A splitattention effect in multimedia learning: Evidence for dual processing systems in working memory, Journal of Educational Psychology 90, 2: 312-320.

McFarlane, A., Sparrowhawk, A. \& Heald Y. (2001) Report on the Educational Use of Games, TEEM (Teachers Evaluating Educational Multimedia), Department for Education and Skills, UK.

Moulthrop, S (1995) 'In the zones: Hypertext and the politics of interpretation' and 'Traveling in the breakdown lane: A principle of resistance for hypertext' (http://raven.ubalt. edu/staff/moulthrop/essays/).

Noble C., \& Bradford W. (2000) Getting it Right for Boys . . . and Girls. London, Routledge.

O'Sullivan, J. (1997) 'Education: A bad way to educate boys', Independent, 04-03-1997, E8-9.

Papert, S. (1998) Interview 'Does easy do IT? Children, games and learning', in Game Developer June, Soapbox Section, p. 88.
Prensky, M. (2001) Digital Game-based Learning. New York, McGraw-Hill

Quigley M. \& Blashki, K. (2003) 'Beyond the sacred garden: Children and the internet', Information Technology in Childhood Education Annual 1: 309-316.

Reiber, L.P. \& Matzko M.J. (2001) 'Serious design for serious play in physics', Educational Technology, 1: 14-24.

Rowe, D. (2004) Sport, Culture and the Media: The Unruly Trinity (2nd ed.). Maidenhead, Open University Press.

Tapscott, D. (1998) Growing Up Digital: The Rise of the Next Generation. New York, McGraw Hill.

West, P. (1999a) 'What does research say about helping boys achieve?', Working Paper No.1, Men and Families Research Group, University of Western Sydney.

West, P. (1999b) 'Boys' underachievement in school: Some persistent problems and some current research', Issues in Educational Research 9, 1: 33-54.

West, P. (2002) Submission to: Inquiry into the Education of Boys, Department of Education and Training, Sydney, N.S.W.

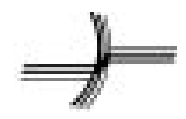

\section{BIOGRAPHICAL NOTE}

Kathy Blashki currently works at Deakin University as Professor of New Media Technologies. She has a diverse range of research interests including narrative and representation in new media, children's interaction with new media and games design and development all of which is suffused with an abiding interest in education. Kathy admits to many many sleepless nights in front of a screen trying to figure out how to move out of the library in Myst. 